\title{
The Most Familiar Stranger: The Acculturation Of Mainland Chinese Students Studying In Taiwan
}

Ren-Fang Chao, I-Shou University, Taiwan

Jih-Rong Yen, Shu-Te University, Taiwan

\begin{abstract}
Mainland China and Taiwan have a homogenous macroculture, but a heterogenous microculture. To understand the acculturation of students from mainland China to Taiwan, the present study applies Berry's (1997) two-dimensional model of acculturation, together with the concept of cultural types as its analytical framework, using focus group interviews to analyze different directions of acculturation among students from mainland China in Taiwan. The results show that regarding personal values, due to Taiwan's restrictions on students from mainland China and the fact that they must eventually return to their place of origin, the acculturation of students from mainland China mainly takes the "separation/segregation" mode. Regarding peer selection, due to differences between individuals in their interpersonal choices, they may adopt "separation/segregation" or "integration" modes. Regarding the period of residence in Taiwan, as students from mainland China spend longer in Taiwan, they tend more towards "integration." However, when teachers show greater contempt for the culture of mainland China, the acculturation of students from mainland China tends toward the "separation/segregation" mode.
\end{abstract}

Keywords: Cultural Conflict; Cultural Stereotypes; Individualism; Collectivism; International Students

\section{INTRODUCTION}

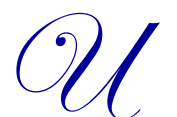

nder the current developments in globalization, the rise of the concept of the knowledge economy has led to a high degree of competition in the international market, with economic success depending on knowledge, and universities playing an even more important role in knowledge creation (Tai, 2005). In addition to the impact of globalization, smaller family sizes and the large increase in the number of colleges and universities have had a significant impact on the development of higher education in Taiwan (Chen, 2015). The shortage of students is already a common problem for many higher education schools. This has made the recruitment of non-Taiwan students a potential solution to the insufficient resources in Taiwan's higher education sector.

Of the many non-Taiwan students, due to their linguistic and cultural similarities, and the close geographical location, students from mainland China have become a potential market that Taiwan's higher education sector has been anxious to develop. They also represent the best way to make up the enrollment gap in Taiwan's higher education sector (Chao, 2013). According to the University Entrance Committee for Mainland Chinese Students (UECMCS), since students from mainland China first came to Taiwan in 2002, their numbers have increased from 348 to 41,981 in 2016 (UECMCS, 2017), showing that students from mainland China are becoming increasingly important for Taiwan's higher education sector.

With the increasing number of students from mainland China in Taiwan's higher education sector, the issue of the acculturation of these students to Taiwan has gradually emerged. However, despite this, Taiwan still lacks research on the cultural adaptation of students from mainland China. For example, Hu (2012) used a narrative analysis approach to analyze changes in the culture shock of students from mainland China who had been in Taiwan for four months. The results of this study found that the acculturation of students from mainland China gradually changed from searching for the familiar strange before arrival in Taiwan to drift and return before their departure from Taiwan. Hu's research confirms the acculturation process for cross-cultural sojourners found by Kim (2002). This phenomenon 
showed despite the homogeneity in language and the geographical proximity between Taiwan and mainland China due to the separation of the two sides for more than 60 years, and differences in political systems and social development within the homogenous culture at the macro level, there is heterogeneity at the micro-cultural level (Chao, 2015; Chao \& Chen, 2016). This cultural heterogeneity has led to a cultural shock on the students from mainland China in Taiwan.

However, Hu (2012) uses a narrative analysis approach, which presents the historical order of events through information about actions, context, and events (Stephens \& Breheny, 2013). However, this type of research has a wide range of limitations. Also, past studies have shown that social and cultural adjustment is closely related to the length of residence (Cheung, Chudek \& Heine, 2011; van de Vijver \& Phalet, 2004; Ward \& Kennedy, 1993). Since the length of time spent in Taiwan by students from mainland China varies depending on the program they are attending, ranging from a single semester to a four-year undergraduate degree, there is a large difference in the time spent in Taiwan. Hu's case study was of an exchange student who spent four months in Taiwan. If we add the time factor to acculturation, we may end up with very different results.

Also, in life, we may feel down or under pressure. For students from mainland China in Taiwan, Chen and Yu's (2014) research identifies that these students often "blame others for negative emotions" rather than "seeking help and communicating." The reasons for this phenomenon may be related to the fact that no communication and trust mechanism between mainland China students and other peers or teachers has been established. Therefore, when adapting to pressure, whether the role of peers and university counseling (role of teacher) is effective may influence the cultural adaptation of students from mainland China in Taiwan. Also, Liu and Hung (2016) also identified that social support is an important factor influencing the learning adaptation of students from mainland China in Taiwan.

The purpose of the present study is to understand the reasons for the acculturation of students from mainland China in Taiwan and to identify the role that Taiwanese teachers play in assisting such acculturation. For analysis, the present study applies Berry's (1997) acculturation model supplemented by the concept of cultural types, using focus group interviews of students from mainland China who were studying at universities in Taiwan to identify acculturation problems.

\section{BERRY'S ACCULTURATION PERSPECTIVE}

Early studies on acculturation have looked at it from the perspective of assimilationism. For example, Gordon (1964) argues that acculturation is a process of evolution toward the mainstream culture. In past policy implementation, the assimilationism perspective led many immigrants to abandon their cultural heritage and adopt the local culture (Schwartz, Unger, Zamboanga \& Szapocznik, 2010), leading to the erosion of the immigrant cultural heritage (Stephens \& Breheny, 2013; Stepick, Stepick \& Vanderkooy, 2011). However, an increasing number of studies have shown that cultural adaptation can also retain a dual cultural identity that includes the original culture of the immigrants and the culture of their place of residence. Thus, the concept of acculturation has gradually evolved from one of assimilationism to a multiculturalism perspective (van de Vijver \& Phalet, 2004).

When sojourners enter a different cultural environment, cultural shock and adjustment are inevitable. Berry (1997; 2006) uses acculturation to explain the complex process of the cultural contact and adjustment of individuals or ethnic groups toward two types of cultures. Berry (1990) defines acculturation as "the process by which individuals change, being determined by both contact with another culture, and by being participants in the general acculturative changes underway in their own culture." During this process, individuals adopt different strategies to choose between their own culture and the culture of their place of residence to adapt to it.

Berry (1997; 2006) uses a two-dimensional model to interpret this relationship. In Berry's (1997; 2006) framework, based on an individual's attitudes and values, acculturation makes a chooses between their original culture and the culture of the place of residence, leading to four possible outcomes between the two cultures: integration, separation/segregation, assimilation, and marginalization.

In Berry's (1997) two-dimensional acculturation model, "assimilation" means the individual or ethnic group gives up their own culture and fully accepts and identifies with the culture of their place of residence. "Integration" means that 
the individual or ethnic group seeks to find a balance between the two cultures. Aside from retaining their traditional culture, they actively participate in and assimilate into the new culture; this is an important aspect of the fusion of different groups in a multiculturalist society. "Separation/segregation" means that the individual or ethnic group follows their original culture and chooses to continue living according to their original culture and traditional values, thus do not accept the culture of their place of residence. "Marginalization" means that individuals or ethnic groups not only lose their original cultural values but are also unable to identify with the culture of their place of residence.

Following a multiculturalism perspective, Berry's (1997) two-dimensional model is believed to be the most pioneering and influential cultural adaptation model for acculturation (Kuo, 2014), but is not an intermediate point in assimilation (Schwartz, Vignoles, Brown \& Zagefka, 2014). In other words, when international students enter the host country, "assimilation" is not the expected result. Instead, the result is trying to reconcile the original culture and the culture of the host country, by creating an adaptive and coherent whole (Benet-Martínez \& Haritatos, 2005). However, this biculturalism is not always easy to achieve (Schwartz et al., 2014). Therefore, the present study used Berry's (1997) two-dimensional model of acculturation to analyze the cultural adaptation of students from mainland China in Taiwan.

\section{ARE THE CULTURE BETWEEN MAINLAND CHINA AND TAIWAN HOMOGENEOUS OR HETEROGENEOUS?}

Typically, during the process of the exchange of international students, the cultural norms of the host country and language barriers are obstacles to their ability to build friendships (Smith \& Khawaja, 2011). To eliminate these barriers and obstacles, many students from mainland China choose Taiwan as their destination for overseas study, due to their shared language and cultural similarities (Hu, 2012; Chen \& Yu, 2014). However, due to past historical factors, mainland China and Taiwan have been separated for a long period and have developed different political ideologies, causing differences to emerge in the cultural values of the two sides (Chao, 2015).

Since acculturation is a process of change that occurs with contact between two or more cultures (Berry, 2005), for the acculturation of international students, the cultural values of the individuals and the host country are important factors influencing acculturation (Schwartz et al., 2014). In the past, discussion of the cultural values of international students has mainly focused on the distinction between individualism and collectivism (Chao \& Chen, 2016; Cook \& Sim, 2015). Triandis (1999) believed that Asian culture is typically collectivist, although there are large differences in the level and type of collectivism. However, when discussing the acculturation of international students in Asia, we must carefully distinguish between the cultural values of different countries.

Chu and Choi (2011) have criticized the dichotomy between individualism and collectivism as too simplistic. In particular, when it is necessary to distinguish between the cultural values of mainland China and Taiwan, due to their close historical origins, this distinction cannot be applied. To address the shortcomings of this dichotomy, Shavitt, Lalwani, Zhang, and Torelli (2006) added horizontal (valuing equality) and vertical (emphasizing hierarchy) dimensions to the one-dimensional model of individualism and collectivism, producing a four-way typology for comparing cultures. This framework divides cultural values into horizontal-individualism (HI), vertical-individualism (VI), horizontal-collectivism (HC), and vertical-collectivism (VC). In this two-dimensional framework, Sivadas, Bruvold, and Nelson (2008) argue that China belongs to the HC type, while Chao and Chao (2016) argue that Taiwan belongs to the HI type. Therefore, although mainland China and Taiwan have homogeneity at the macro level, they have heterogeneity at the micro level (Chao, 2015).

Yeh and Inose (2003) found that due to differences between individualism and collectivism, international students from Asia may encounter difficulties when interacting with Western culture, showing differences in cultural values that will affect their acculturation. Therefore, as mainland China and Taiwan belong to different cultural types, the exchange and interaction process for international students will also be affected. For this reason, in the subsequent discussion, in addition to Berry's (1997) two-dimensional model for an acculturation framework, the present study also includes the concept of the cultural heterogeneity between mainland China and Taiwan in its analysis. Here, we analyze the cultural adaptation of students from mainland China on dimensions such as value choices between the original culture and the culture of the place of residence, the external environment (counseling support), and interpersonal interactions. 


\section{METHODOLOGY}

We collected the views of students from mainland China on acculturation when studying in Taiwan, using the focus group method. This method is used to listen to and gather social information (Krueger \& Casey, 2009), and construct meaning (Bryman \& Bell, 2007), which offers a good strategy for the collection of large amounts of data in a short time (Fusch \& Ness, 2015). For these methods, at least three focus group sessions should be organized, with each session usually composed of 5-10 people (Fusch \& Ness, 2015; Krueger \& Casey, 2009). According to the above principles, the present study organized focus group sessions at three private universities in Northern, Central, and Southern Taiwan, inviting seven students to each session. The students attending the focus group interviews were invited through the administrative units at each of the three universities and participated willingly. The seven students at each of the universities included three students on four-year degree programs, and four exchange students staying in Taiwan for between four months and one year, to include students with different lengths of stay in Taiwan. We interviewed with the consent of the interviewees and produced interview notes. After the interview, a verbatim record of the interview was made using the recording, which was confirmed to be correct by the interviewees. We then classified and analyzed the content. Based on past research results (Chen \& Yu, 2014; Hu, 2012; Liu \& Hung, 2016), we developed the following outline for interview topics:

- Motivations and views about studying in Taiwan.

- Life experiences, social interaction, interpersonal relationships, and overall perception of Taiwan.

- View of learning outcomes in Taiwan.

- Perceptions of Taiwanese society.

- Opinions on the Taiwanese Ministry of Education's policy for students from mainland China in Taiwan.

\section{FACTORS IMPACTING THE ACCULTURATION OF MAINLAND CHINESE STUDENTS IN TAIWAN}

When discussing the acculturation of students from mainland China in Taiwan, it is first necessary to define important influencing factors. This issue can be discussed from the physiological, psychological and social needs, as well as the interaction between individuals and the environment. Tsai, Lin, Chen, and Cheng (2012) identified five factors of acculturation that affect the life adaptation of students from mainland China in Taiwan. These are physical health adaptation, interpersonal adaptation, local cultural adaptation, living environment adaptation, and economic status. The problem with these dimensions is that they ignore the views of respondents on their own culture and the culture of their place of residence, as well as the impact of length of time on acculturation. Yet, according to the concept of acculturation, cultural adaptation is closely related to how individuals view their own culture and the culture of their place of residence (Schwartz et al., 2014), and the length of stay also affects the outcome of life adaptation (Cheung et al., 2011; van de Vijver \& Phalet, 2004; Ward \& Kennedy, 1993). Therefore, the following discussion of the acculturation of students from mainland China in Taiwan will look at the dimensions of personal values, peer selection, length of time in Taiwan, and teacher-student relationships.

\section{Personal Values}

When two cultures come into contact, the most obvious phenomenon is how individuals view their own culture and the culture of their place of residence. This issue therefore involves questions of cultural identity. Licata, SanchezMazas, and Green (2011) argued that the key determinants of the process and outcome of acculturation is whether group members believe that their cultural identity is threatened by the presence or behavior of other groups. Initially, the concept of acculturation tended toward assimilationism, based on the choices made when a weaker culture comes up against a stronger culture. However, students from mainland China coming to Taiwan to study do not represent a weak culture entering a strong culture, but rather a process of equal cultural exchange. In particular, one of the goals of the promotion of the "Chinese dream" under Xi Jinping's leadership is to strengthen national/cultural identity (Wang, 2014). Therefore, students from mainland China do not perceive themselves to be a weak culture entering into a strong culture. However, as the following interview data show, with regards to the attitude of the Taiwanese toward mainlanders, there is still a relationship between a strong culture and a weak culture, so the first culture shock faced by many students from mainland China in Taiwan is an unfriendly attitude toward their own culture in their place of residence. 
After a long period of cross-Strait exchanges, I found that the impression of the mainlanders in Taiwan is still stuck in the past. (Interview record: 140523-5-4)

I think you need to adjust your views when faced with these popular misconceptions ....so that more people in Taiwan understand that the mainliners now are not the same as the only concept of the mainlanders. (Interview record: 140523-2-3)

Faced with this phenomenon of cultural difference, O'Reilly (2000) argues that unlike immigrants, sojourners eventually tend to return home, and will therefore idealize their place of origin. Due to Taiwan's various restrictions, students from mainland China cannot stay in Taiwan for work, and must eventually return to their place of origin. Under such circumstances, when their own culture is threatened or undermined, they will strengthen their own cultural identity (Schwartz et al., 2014). Therefore, according to $\mathrm{Hu}$ (2012), students from mainland China will use empathy to re-construct the relationship between their own culture and their place of residence, thus rationalizing their culture shock in Taiwan. This compromise in social interaction, is a mode of self-adjustment to achieve social harmony, and fully displays the features of the horizontal-collectivism culture type.

Cross-strait cultural shock may also be related to whether students from mainland China have an understanding of Taiwan prior to their arrival. In the interview process, some students from mainland China (mainly students coming to Taiwan for four-year degrees), chose Taiwan because they did not perform well on the university entrance examination in mainland China. When they lacked an adequate understanding of Taiwan, they faced a bigger culture shock in the initial period.

In addition, for students from mainland China, individual value choices may also result in different cultural adaptation outcomes due to cultural tendencies. In particular, for education systems and methods, a majority of students from mainland China supported education methods in Taiwan, which were very different from university education in mainland China. Thus, attitudinally, they supported Taiwan's education system. A number of cases also show that students who identify with university education in Taiwan may choose to return to Taiwan for graduate studies after they have completed one semester as exchange students in Taiwan.

In general, in terms of the impact of personal values on cultural adaptation, how students adapt to their own culture and the culture of their place of residence may need to be looked at from different perspectives, rather than assuming that each of the dimensions are consistent. In contrast to Berry's $(1997 ; 2006)$ cultural adaptation model, in terms of the overall culture, students from mainland China tend toward the "separation/segregation" mode, but for the education dimension, we find the "assimilation" cultural adaptation mode.

\section{Peer Selection}

In the horizontal-collectivism culture type, emphasis on social interactions is an important feature (Shavitt et al., 2006). Generally speaking, students from mainland China will adopt more sociable personalities; however, during their peer selection, we can identify two alternative choices. The first is a tendency to interact with students from mainland China, and the second is a tendency to interact with Taiwanese students. Respondents who tended to interact with students from mainland China were usually unconcerned about culture shock from a heterogenous culture, and had a stronger sense of cultural self-identity, thus clearly belong to the "separation/segregation" type. Yet because these types of students were all short-term exchange students who would return to their place of origin after four months of study, they had no possibility of changing from the "separation/segregation" mode to the "marginalization" mode.

Students from mainland China who chose to interact more with Taiwanese students typically had a preference for or understanding of Taiwan prior to their arrival. For example:

I started liking Taiwan in my third year of junior high school. Since my first year of senior high school when I found out about this opportunity, I worked hard toward my goal of coming to Taiwan for my studies.... I wanted to experience different cultures, and have more diversified learning, forging my own independence ...When I was on the mainland, I mainly learned about Taiwan through Taiwanese TV dramas. (Interview record: 140514-1-2) 
I have liked Taiwan since I was a child. My idols are S.H.E from Taiwan. I had the opportunity to apply, and when I was admitted, I naturally came to Taiwan. (Interview record: 140514-1-3)

Because of their preference for Taiwan, these students from mainland China were more concerned about the culture shock faced when they got to Taiwan. With regard to cultural differences between the two sides of the Taiwan Strait, Huang, Jia, Lin, and Yeh (2013) argued that Taiwanese people "do not understand" rather than "misunderstand" mainland China. Under such circumstances, although the students from mainland China must eventually return home, frequent exchanges with Taiwanese students can quickly resolve "misunderstandings," and reduce culture shock. At the same time, they are also able to adapt to Taiwan's cultural context more quickly, creating the possibility for an "integration" mode of cultural adaptation.

Frequent exchanges between students from mainland China and Taiwanese students may occur via romances between students. Huang et al. (2013) argued that such individuals often ignore their identity as "Taiwanese" or a "mainlander," as long as there is a tacit agreement to "avoid talking about politics," it is easier to overcome the cultural gap. However, Huang et al. (2013) also pointed out that romance between students from mainland China and Taiwanese students may result in the reluctant choice, in the classic lines of the movie Cape No. 7: "stay here, or I go with you." Because mainland China strictly controls the overseas travel of its residents, Chen (2012) argues that when students from mainland China and Taiwanese students "are still together," it is because the male Taiwanese student plans to work in mainland China. Yet, if we put aside emotional factors, romances between mainland and Taiwanese students are the quickest way to eliminate cultural shock. This is therefore a case of the "integration" mode of cultural adaptation.

\section{Length of Time in Taiwan}

In terms of the educational system, students from mainland China studying in Taiwan may stay for four months, one year, or four years. The largest number of students come to Taiwan for four months (one semester). Because these students only spend a short term in Taiwan, they have an obvious sojourner mentality, for example:

On the mainland, the academic pressure is very high, it's very tiring. I would like to have a change of environment and seek new possibilities. On the mainland, I am sometimes at a loss academically, and don't have time to think about what I want. So I want to relax for a while and try Taiwan. (Interview record: 140523-1-5)

I want to experience Taiwan's human culture and island scenery. (Interview record: 140514-1-7)

The sojourner mentality means that when students from mainland China face culture shock, they do not actively respond or adapt, as they are only spending a short time in Taiwan. This is also related to the peer selection described above. Students from mainland China with a sojourner mentality prefer to spend time with other mainland students, meaning they tend toward the "separation/segregation" mode of acculturation. However, some short-term exchange students are more concerned about experiencing Taiwan's culture and lifestyle. For example, in Hu's (2012) case study, because these students were aware that they only had a short time in Taiwan, when faced with culture shock, they continued to reflect, adapt, and rebuild, in order to achieve an appropriate balance and response at the psychological level. This represents a rapid and dynamic change from the "separation/segregation" type to the "integration" type.

Students from mainland China studying for degrees in Taiwan cannot simply view life in Taiwan with a sojourner mentality, Because they are in Taiwan for longer, they have to achieve an appropriate level of the "integration" mode of cultural adaptation. These degree students who must spend four years in Taiwan, face the problem of cultural adjustment. As one degree student described it:

I feel Taiwan is very friendly, so I have good feelings about it, but at the beginning, I wasn't able to open up. After getting to know people for two years, this isn't a problem anymore...Public opinion in Taiwan is a problem I frequently encounter, but you just have to deal with it rationally. As long as your Taiwanese student friends understand, then it's no problem. (Interview record: 140523-2-2) 
Obviously, the initial gap takes time to overcome. Cultural adaptation may be related to individual traits. However, if students with weaker cultural adaptability choose a short-term exchange, then the "separation/segregation" type may appear. However, if they are degree students, they are forced to face up to adapting to the culture of their place of residence. Under such circumstances, "time" becomes an important factor (Ward \& Kennedy, 1993). In other words, time can make the "integration" mode possible.

\section{Teacher-Student Relationships}

Aside from the influence of peers, teachers also play an important role in the interpersonal relationships of students from mainland China in Taiwan. In fact, teacher-student relationships in Taiwanese education are closer than those in mainland China, especially at the undergraduate level. This may be due to mainland China's vast size; there are long distances between different campuses. Thus, because teachers have to spend time in the community between different campuses and teachers may lack time to keep in close contact with students. As time passes, students in Mainland China may lack opportunities and habits for teachers and students to interact with each other. Based on the author's experience of short-term teaching in mainland China, teachers do face space and time constraints, which produces a sense of distance between teachers and students (Interview record: 140522-3-5). Tsai et al. (2012) also found that students from mainland China had closer interactions with their teachers than with classmates. With regards to the teacher-student relationship, the present study explores the influence of teachers on the life of students from mainland China, rather than teaching methods or teacher counseling. Therefore, the views of teachers on students from mainland China in Taiwan will affect the acculturation of their students. For example:

The teachers are all excellent. In class, they pay attention to the students from mainland China and also encourage exchanges between Taiwanese and mainland students in the class. (Interview record: 140523-34)

I feel that Taiwanese teachers and students have a discriminatory attitude toward students from mainland China. Although most of the teachers are very good, I also will encounter a small number of teachers that have a contemptuous attitude, which makes you feel frustrated. (Interview record: 140522-2-1)

From these interviews, we find that the close relationships between teachers and students from mainland China mean that the attitude of teachers affects the emotions and acculturation of students from mainland China. Hu's (2012) case study produced a similar result: there was frequent contact between mainland students and teachers, and one student felt that although the teacher looked after him, he frequently laughed at the language used in the service industry in mainland China, resulting in the student experiencing a major culture shock. Hu (2012) explained that the student is not arguing with his teacher, but with local students who have stereotypes of mainlanders as "backward and uncivilized." $\mathrm{Hu}$ (2012) argues that this phenomenon will strengthen the positive feelings and longing of students from mainland China for their place of origin. According to the "identification" perspective proposed by Brubaker and Cooper (2000), marking the self and others in a slightly contemptuous way will strengthen the cultural identity and consciousness of students from mainland China toward their own culture, producing the "separation/segregation" type. This also shows that teachers' attitude towards mainland students to Taiwan will affect their cultural identity and acculturation. The personal values of teachers may promote or inhibit the acculturation of students from mainland China. 


\section{CONCLUSION}

Due to historical factors, there is a special type of relationship between mainland China and Taiwan. Although Taiwan and mainland China are a homogeneous culture macroscopically, due to more than 60 years of separation, and differences in political systems and social development, in the homogenous microculture between mainland China and Taiwan, there is microcultural heterogeneity. Therefore, although the two sides share similar language and culture, an encounter between the two will still produce differing levels of culture shock.

About acculturation, this study uses the two-dimensional model proposed by Berry $(1997 ; 2006)$ as its analytical framework. According to Berry $(1997 ; 2006)$ when there is an encounter between two cultures, four different outcomes are possible: integration, separation/segregation, assimilation, and marginalization. On this basis, the present study looked at the dimensions of personal values, peer selection, length of time in Taiwan, and teacher-student relationships, discussing how different factors influence the acculturation of students from mainland China studying in Taiwan when they encounter cultural shocks.

Regarding the influence of personal values on acculturation, due to Taiwan's restrictions on students from mainland China, they must eventually return to their place of origin. Therefore, the acculturation of such students mainly takes the form of the "separation/segregation" mode. However, from the perspective of the education system, the university education system and the current situation are still attractive for students from mainland China. Therefore, the education dimension tends toward the "assimilation" cultural adaptation mode.

Regarding the influence of peer selection on acculturation, the tendencies of students from mainland China have two different types. The first is the tendency to develop close peer relations with other students from mainland China, and the second is the tendency to develop close peer relations with Taiwanese students. The former tends toward the "separation/segregation" type of acculturation; the latter contains the possibility of the "integration" type. Also, romances between students from mainland China and Taiwanese students are a special type of peer relationship.

In this context, the acculturation of students from mainland China has a clear "integration" tendency.

Regarding the impact of length of time in Taiwan on acculturation. For four-month short-term exchange students, the sojourner mentality tends to produce a "separation/segregation" type of acculturation. However, some short-term exchange students still look forward to cultural experiences and learning. For this type of student, the mode of acculturation gradually changes from the "separation/segregation" type to the "integration" type. For the degree students who spend four years in Taiwan, because of their long-term need to live in Taiwan, they move over time towards the "integration" type.

For the impact of teacher-student relationships on acculturation, because, aside from peers, teachers are the most important network of interpersonal relations for students from mainland China in Taiwan, their attitude also impacts the acculturation of students from mainland China. In regards to how teachers affect the acculturation tendencies of students from mainland China, we need to consider the teacher's attitudes. When teachers are more contemptuous toward the culture of mainland China, this produces the "separation/segregation" type of acculturation among mainland students. Conversely, if teachers take a tolerant and multi-cultural perspective, then the acculturation among students from mainland China will develop towards the "integration" type.

In this study, we focused on the factors that affect the acculturation of students from mainland China. However, cultural interaction is a dynamic process (Schwartz et al., 2014). With the increasing interactions across the Taiwan Strait, each side will also display different progress in social and economic development, and there may also be changes in cultural conflict and adaptation. Therefore, in the future, we plan to do follow-up studies on the acculturation of students who have returned to mainland China, to understand the acculturation problems of students who have already integrated Taiwanese culture before returning to the mainland. Also, the number of Taiwanese students studying in mainland China is also increasing. The question of whether Taiwanese students face similar acculturation problems in mainland China is also worthy of future attention. 


\section{AUTHOR BIOGRAPHIES}

Ren-Fang Chao is an associate professor at the Department of Leisure Management in I-Shou University, Taiwan. He is currently serving as an associate editor of the journal "Policy and Personnel Management" and the editor board of "Journal of Contemporary Educational Research." His research interests include environmental education, cultural sociology, indigenous education, educational policy, higher education, and career counseling. He is an excellent teacher of I-Shou University, and has several academic articles on student learning and cultural adaptation.

Jih-Rong Yen is a professor at the Department of Distribution Management in Shu-Te University. He earned his PhD from Graduate Institute of Education Administration, National Pingtung University. He is currently Vice President of Shu-Te University, and is responsible for international exchange, management and strategic development. His research interests include education administration, public relations, human resource management, and leadership. In addition, there are unique achievements in the study of higher education, and published several related academic articles.

\section{REFERENCES}

Benet-Martínez, V., \& Haritatos, J. (2005). Bicultural identity integration (BII): Components and psychosocial antecedents. Journal of Personality, 73, 1015-1050.

Berry, J. W. (1990). Psychology of acculturation. In J. Berman (Ed.), Cross-cultural perspectives: Nebraska Symposium on Motivation (pp. 201-235). Lincoln: University of Nebraska Press.

Berry, J. W. (1997). Immigration, acculturation, and adaptation. Applied Psychology: An International Review, 46, 5-68.

Berry, J. W. (2005). Acculturation: Living successfully in two cultures. International Journal of Intercultural Relations, $29,697-$ 712.

Berry, J. W. (2006). Contexts of acculturation. In D. L. Sam \& J. W. Berry (Eds.), Cambridge Handbook of Acculturation Psychology, (pp. 27-42). Cambridge, UK: Cambridge University Press.

Brubaker, R., \& Cooper, F. (2000). Beyond "identity". Theory and Society, 29(1), 1-47.

Bryman, A., \& Bell, E. (2007). Business Research Methods. Oxford: Oxford University Press.

Chao, C.-Y. (2013). An analysis of the studying achievements of mainland Chinese students in Taiwan. Prospect and Exploration, 11(5), 69-91. (In Chinese)

Chao, R.-F. (2015). The acculturation of Taiwanese internship students in mainland China: A narrative analysis approach. 2015 Proceedings of Educational Forum on Employment Service and Career Development in Cross-Strait Universities, Taichung, Taiwan. (In Chinese with English abstract)

Chao, R.-F., \& H.-F. Chen. (2016). The effect of product involvement on the relationship between electronic word-of-mouth and purchase intention: The cross-cultural comparison between Taiwan and Mainland China. Journal of Global Business Management, 12, 121-131.

Cheung, B. Y., Chudek, M., \& Heine, S. J. (2011). Evidence for a sensitive period for acculturation: Younger immigrants report acculturating at a faster rate. Psychological Science, 22, 147-152.

Chen, R. J. (2015). Public and private universities in Taiwan: To compete or not to compete? RIHE International Seminar Reports, 23, 101-118.

Chen, Y.-F. (2012). My love credits: The love between mainland Chinese student and Taiwanese student. Seminar on CrossStrait Higher Education, New Taipei, Taiwan. (In Chinese)

Chen, Y.-J., \& Yu, Y.-C. (2014). Social support and coping strategies of students from China in Taiwan: A case of private university of Technology. School Administration, 92, 65-84. (In Chinese with English abstract)

Cook, K. V., \& Sim, D. (2015). Acculturation of Korean multicultural Christian college students. Journal of Psychology and Christianity, 34(1), 53-60.

Chu, S. C., \& Choi, S. M. (2011). Electronic word-of-mouth in social networking sites: A cross-cultural study of the United States and China. Journal of Global Marketing, 24(3), 263-281.

Fusch, P. I., \& Ness, L. R. (2015). Are we there yet? Data saturation in qualitative research. The Qualitative Report, 20(9), 14081416.

Gordon, M. M. (1964). Assimilation in American life: The Role of Race, Religion, and National Origins. New York: Oxford University Press.

Hu, S.-C. (2012). Reflections on journeying to Taiwan: A PRC Student's intercultural narrative and identity reconstruction. Mass Communication Research, 111, 43-87. (In Chinese with English abstract)

Huang, C.-H., Jia, S.-L., Lin, T., \& Yeh, J.-X. (2013). The First Year of Mainland Chinese Students. Taipei, Taiwan: Showwe Information. (In Chinese)

Kim, Y. Y. (2002). Adapting to an unfamiliar culture: An interdisciplinary overview. In W. B. Gudykunst \& B. Mody (Eds.), Handbook of International and Intercultural Communication, 259-273. Thousand Oaks, CA: Sage. 
Krueger, R. A., \& Casey, M. A. (2009). Focus Groups: A Practical Guide for Applied Research (4 ${ }^{\text {th }}$ Ed.). Thousand Oaks, CA: Sage.

Kuo, B. C. (2014). Coping, acculturation, and psychological adaptation among migrants: a theoretical and empirical review and synthesis of the literature. Health Psychology and Behavioral Medicine: An Open Access Journal, 2(1), 16-33.

Licata, L., Sanchez-Mazas, M., \& Green, E. G. T. (2011). Identity, immigration, and prejudice in Europe: A recognition approach. In S. J. Schwartz, K. Luyckx, V. L. Vignoles (Eds.), Handbook of Identity Theory and Research, 895- 916. New York: Springer.

Liu, Y. C., \& Hung, Y. Y. (2016). Self-efficacy as the moderator: Exploring driving factors of perceived social support for mainland Chinese students in Taiwan. Computers in Human Behavior, 64, 455-462.

O'Reilly, K. (2000). The British on the Costa del Sol: Transnational Identities and Local Communities. London, UK: Routledge.

Schwartz, S. J., Unger, J. B., Zamboanga, B. L. \& Szapocznik, J. (2010). Rethinking the concept of acculturation: Implications for theory and research. American Psychologist, 65, 237-251.

Schwartz, S. J., Vignoles, V. L., Brown, R., \& Zagefka, H. (2014). The identity dynamics of acculturation and multiculturalism: Situating acculturation in context. In V. Benet-Martinez, \& Y. Y. Hong (Eds.), Handbook of Multicultural Identity: Basic and Applied Psychological Perspectives (pp. 57-93). Oxford, UK: Oxford University Press.

Shavitt, S., Lalwani, A. K., Zhang, J., \& Torelli, C. J. (2006). The horizontal/vertical distinction in cross-cultural consumer research. Journal of Consumer Psychology, 16(4), 325-342.

Sivadas, E., Bruvold, N. T., \& Nelson, M. R. (2008). A reduced version of the horizontal and vertical individualism and collectivism scale: A four-country assessment. Journal of Business Research, 61(3), 201-210.

Smith, R. A., \& Khawaja, N. G. (2011). A review of the acculturation experiences of international students. International Journal of Intercultural Relations, 35(6), 699-713.

Stephens, C., \& Breheny, M. (2013). Narrative analysis in psychological research: An integrated approach to interpreting stories. Qualitative Research in Psychology, 10(1), 14-27.

Stepick, A., Stepick, C. D., \& Vanderkooy, P. (2011). Becoming American. In S. J. Schwartz, K. Luyckx, \& V. L. Vignoles (Eds.), Handbook of Identity Theory and Research (pp. 867-893). New York: Springer.

Tai, H.-H. (2005). Globalization and the pursuit of academic excellence. Proceedings of University Ideas and University Education in the Era of Globalization. National Taiwan University, Taipei, Taiwan. (In Chinese)

Triandis, H. C. (1999). Cross-cultural psychology. Asian Journal of Social Psychology, 2, 127-143.

Tsai, T.-H., Lin, T.-J., Chen, Y.-P., \& Cheng, Y.-F. (2012). A Study of life adjustment and learning satisfaction of mainland China students in Taiwan. Journal of Chinese Trend and Forward, 8(2), 15-42. (In Chinese with English abstract)

UECMCS. (2017). Enrollment Data of Mainland Chinese Students. Retrieved August 25, 2017, from http://rusen.stust.edu.tw/cpx/member.html. (In Chinese)

van de Vijver, F. J., \& Phalet, K. (2004). Assessment in multicultural groups: The role of acculturation. Applied Psychology, 53(2), 215-236.

Wang, Z. (2014). The Chinese Dream: Concept and Context. Journal of Chinese Political Science, 19(1), 1-13.

Ward, C., \& Kennedy, A. (1993). Where's the culture in cross-cultural transition? Comparative studies of sojourner adjustment. Journal of Cross-Cultural Psychology, 24, 221-249.

Yeh, C. J. \& Inose, M. (2003). International students' reported English fluency, social support satisfaction, and social connectedness as predictors of acculturative stress. Counselling Psychology Quarterly, 16(1), 15-28. 